\title{
Decoupling of dissolved and particulate Li isotopes during estuarine processes
}

\author{
C. Yang ${ }^{1,2}$, N. Vigier ${ }^{2}$, E. Lian ${ }^{1}$, Z. Lai ${ }^{1}$, S. Yang ${ }^{1 *}$
}

Abstract

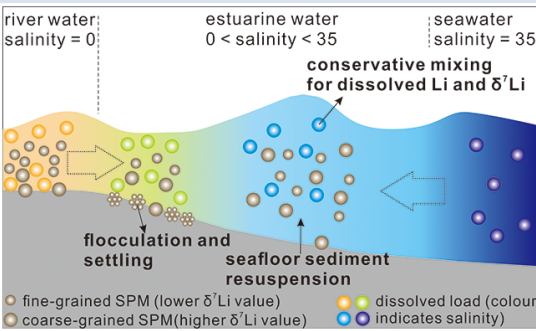

Lithium isotopes in marine authigenic or detrital sedimentary archives have been recently used to trace continental weathering over geologic timescales. However, interpretations are predominantly based on the assumption that riverine $\mathrm{Li}$ isotopic signals can be propagated through estuaries without modification. Here, we verify this hypothesis by investigating the behaviour of Li isotopes in the Changjiang (Yangtze) River estuary. We observe a conservative mixing of dissolved Li and its isotopes between the Changjiang River water and seawater. The dissolved $\delta^{7} \mathrm{Li}$ yields a non-linear increase with salinity, and a significant increase occurs during the initial water mixing. Through the studied transect, estuarine flocculation and resuspension processes cause the homogenisation of offshore particulate $\delta^{7} \mathrm{Li}$ values, which are close to the average composition of upper continental crust. This study provides clear and direct evidence that the riverine dissolved $\mathrm{Li}$ isotopic signal is not modified during estuarine processes in large rivers, but caution should be exercised when using detrital $\delta^{7} \mathrm{Li}$ in marginal seas to investigate past continental weathering.

Received 19 May 2021 | Accepted 22 September 2021 | Published 3 November 2021

\section{Introduction}

As critical interfaces between continents and oceans, estuaries typically feature gradients of ionic strength and suspended particle concentration, providing an ideal environment for studying land-sea and water-sediment interactions. Over the last decades, numerous studies have demonstrated that riverine elemental fluxes and isotope compositions (e.g., $\mathrm{Si}, \mathrm{Sr}$, and $\mathrm{Nd}$ ) can be modified by physical, chemical, and/or biological processes during their transport through estuaries (Lacan and Jeandel, 2005; Jones et al., 2012, 2014; Zhang et al., 2020). For instance, the dissolution of basaltic particles and $\mathrm{Ca}-\mathrm{Na}$ exchange on clay minerals in saline water were considered to play non-negligible roles in global climate stabilisation (Gislason et al., 2006; Tipper et al., 2021). Investigating elemental and isotopic alteration of particles and water in estuaries is thus essential for a better understanding of oceanic elemental cycles, and of the carbon cycle in particular.

River $\mathrm{Li}$ isotopes $\left(\delta^{7} \mathrm{Li}\right)$ are thought to be a powerful proxy of continental weathering (Huh et al., 1998; Wang et al., 2015; Dellinger et al., 2017). During weathering processes, the light ${ }^{6} \mathrm{Li}$ isotope is preferentially incorporated into the solids, causing the dissolved phase to be isotopically heavy. To date, $\mathrm{Li}$ isotopes registered in bulk carbonate or detrital sedimentary archives have been widely applied to assess changes of continental weathering regimes during mass extinctions and long or short term global warming/cooling events (Misra and
Froelich, 2012; Pogge von Strandmann et al., 2013; Bastian et al., 2017; Yang et al., 2021). All these studies implicitly or explicitly assume that riverine $\mathrm{Li}$ fluxes to the ocean and their isotopic signals behave conservatively in estuaries. However, thus far, this assumption has not been verified over large scales. Indeed, few case studies have highlighted either the conservative or non-conservative behaviour of $\mathrm{Li}$ isotopes in small estuaries (Pogge von Strandmann et al., 2008; Murphy et al., 2014). For instance, Pogge von Strandmann et al. (2008) observed an increase of particulate $\delta^{7} \mathrm{Li}$ values (from $\sim 0 \%$ o to $\sim 5 \%$ o) along a transect in the Borgarfjörður estuary (Iceland) related to ongoing weathering of suspended particles.

Major rivers in Asia, such as the Changjiang (Yangtze) River (Fig. S-1a), drain large continental basins and deliver huge amounts of detrital particles, dissolved elements, and nutrients to the marginal seas and oceans. Detailed investigations of elemental geochemical behaviours in these estuaries provide constraints on the application of $\mathrm{Li}$ isotopes as a robust weathering proxy. We present $\mathrm{Li}$ isotopic data for the dissolved load, suspended particulate matter (SPM), and their exchangeable phase (see Supplementary Information) in the Changiang River estuary (Fig. S-1). Our primary goal is to investigate the dissolved and particulate $\mathrm{Li}$ isotopic compositions during the mixing processes, and to evaluate the propagation and alteration of terrestrial $\mathrm{Li}$ isotopic signals in a large, turbid, and highly dynamic river estuary.

\footnotetext{
State Key Laboratory of Marine Geology, Tongii University, 1239 Siping Road, Shanghai 200092, PR China

Oceanography Laboratory of Villefranche (LOV), CNRS, Sorbonne University, 06230 Villefranche-sur-Mer, France

Corresponding author (email: syyang@tongii.edu.cn)
} 


\section{Evidence for Conservative Mixing of Dissolved $\mathrm{Li}$ and $\delta^{7} \mathrm{Li}$}

As shown in Figure 1a, the dissolved Li concentrations are linearly correlated with salinity, suggesting that the Li-poor Changjiang River water and Li-rich seawater are the only two major contributors of dissolved $\mathrm{Li}$ in the mixing zone. This salinity-Li relationship is consistent with observations made in the St. Lawrence estuary and the Gulf of Papua (Stoffyn-Egli, 1982; Brunskill et al., 2003). However, the use of Li concentrations alone does not permit identification of all the processes potentially occurring in the mixing zone. Indeed, as indicated by experimental investigations and by previous studies of Icelandic estuaries, isotopic exchanges may modify riverine dissolved isotopic compositions without significantly affecting elemental concentrations (Jones et al., 2012, 2014). When we report the dissolved $\delta^{7} \mathrm{Li}$ as a function of the inverse of the $\mathrm{Li}$ concentration (Fig. 1b), all the samples are distributed along the theoretical mixing line between the Changjiang River water and seawater. These results a priori support the conservative behaviour of the dissolved $\mathrm{Li}$ and its isotopes along the studied transect.

The relatively high seawater Li concentration may mask some of the Li release during SPM dissolution (Morin et al., 2015) or Li uptake by SPM (Pogge von Strandmann et al., 2008). The dissolution rates of quartz, albite, and clays, which are major constituent minerals of Changjiang SPM, are relatively slow, because they have undergone intermediate to strong chemical weathering in the catchment. For instance, less than $0.1 \%$ of kaolinite and illite would be expected to dissolve in seawater annually (Jeandel and Oelkers, 2015). As a first approximation, we can assume that $0.1 \%$ of the SPM Li could be released by dissolution in the Changjiang Estuary, although the average residence time of the Changiiang diluted water plume is only $5.4 \mathrm{~d}$ (Gu et al., 2012). A mass balance model suggests that, in that case, the dissolved $\delta^{7} \mathrm{Li}$ would decrease by $\sim 0.2 \%$ o (see Supplementary Information), which is within analytical uncertainties. For the possible influences of Li uptake, modelling results suggest that the dissolved $\delta^{7} \mathrm{Li}$ values would be significantly altered in the maximum turbidity zone where suspended sediment concentration can reach $\sim 2 \mathrm{~g} / \mathrm{L}$ (for detailed calculations, see Supplementary Information and Fig. S-2). This is apparently inconsistent with the conservative behaviour of dissolved $\mathrm{Li}$ and $\delta^{7} \mathrm{Li}$ observed in this study (Fig. 1). Thus, we suggest that the influence of sediment-water interactions on dissolved $\mathrm{Li}$ is insignificant in the Changjiang Estuary. Additionally, submarine groundwater discharge (SGD, $0.2-1.0 \times 10^{9} \mathrm{~m}^{3} \mathrm{~d}^{-1}$ ) was estimated to be $6-30 \%$ of the river discharge during the flooding season in the Changjiang Estuary (Gu et al., 2012). Although no Li data were reported for this discharge, our results imply that the SGD plays a small role in the isotope compositions of the Li flux to the East China Sea. A similar conclusion has been drawn by Bagard et al. (2015) for assessing the modern $\mathrm{Li}$ isotopic budget of the ocean, based on investigation of the $\mathrm{Li}$ flux and $\delta^{7} \mathrm{Li}$ of groundwater in the Ganges-Brahmaputra downstream basin.

The conservative mixing of dissolved $\mathrm{Li}$ and $\mathrm{Li}$ isotopes observed in the Changjiang Estuary exhibits a nonlinear $\delta^{7} \mathrm{Li}$ variation as a function of salinity. Indeed, the dissolved $\delta^{7} \mathrm{Li}$ values increase significantly in the head of the estuary, during the initial mixing between river water and seawater (Fig. 1b). This is because seawater is enriched in $\mathrm{Li}$ and isotopically heavy compared to river water. We calculate that the addition of $1 \%$ seawater to the Changiiang River water causes the $\delta^{7} \mathrm{Li}$ value to increase by $3 \%$ (Supplementary Information). When salinity exceeds $7 \%$, the dissolved $\delta^{7} \mathrm{Li}$ value remains more or less constant (between $\sim 30 \%$ ond $31.6 \%$ o). Due to differences in catchment lithologies, climate regimes, and other environmental parameters, the dissolved $\mathrm{Li}$ concentrations and $\delta^{7} \mathrm{Li}$ values of river waters worldwide yield significant spatial and seasonal variations. Nevertheless, as discussed above, physical mixing of different water masses cannot modify the conservative behaviours of dissolved $\mathrm{Li}$ and $\mathrm{Li}$ isotopes in estuaries. Therefore, the fast response and significant variation of riverine $\delta^{7} \mathrm{Li}$ to a small volume of seawater addition observed in this study
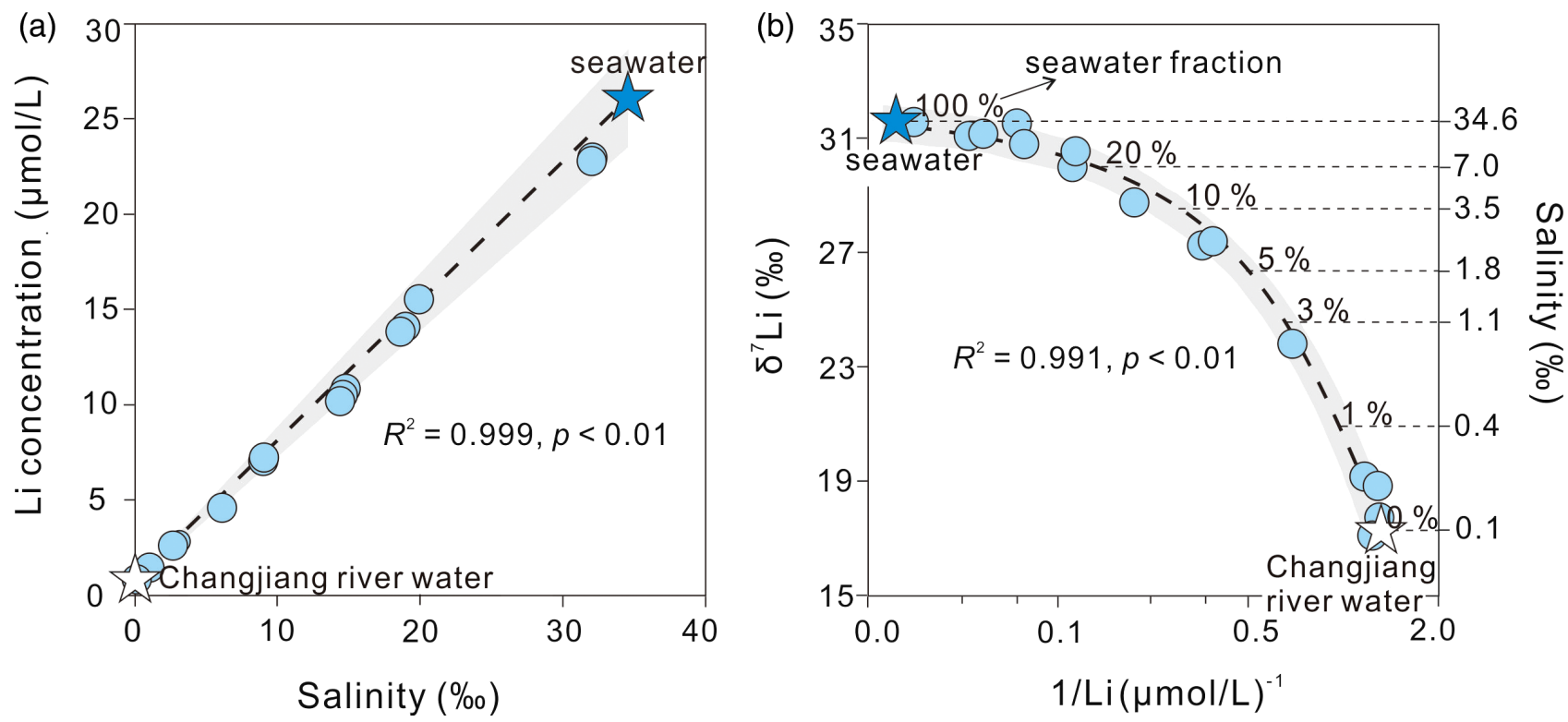

Figure 1 (a) Variations of dissolved Li concentration as a function of salinity, and (b) variations of dissolved $\delta^{7}$ Li as a function of the inverse of the molar Li concentration (1/Li). The $x$-axis in (b) is logarithmic. The dashed lines and shaded areas represent calculated conservative mixing between seawater (dark blue star) and Changjiang River water (white star). The mass balance model is provided in the Supplementary Information. The shaded areas are estimated using the Monte Carlo method, given that analytical uncertainties in Li concentrations and $\delta^{7} \mathrm{Li}$ are $10 \%$ and $0.6 \%$, respectively. The analytical uncertainty for each $\delta^{7} \mathrm{Li}$ value is smaller than the symbol size. 
is expected to be universal. Indeed, in most large rivers, dissolved Li concentrations are two orders of magnitude lower than that of seawater, and $\delta^{7} \mathrm{Li}$ values are $5-10 \%$ less (Huh et al., 1998). Caution must therefore be paid to this effect when sampling rivers at their mouths for quantifying their contribution of $\mathrm{Li}$ and $\delta^{7} \mathrm{Li}$ flux to the ocean.

\section{Particulate Li and $\delta^{7} \mathrm{Li}$ Behaviour in the Estuary}

At the XLJ gauging station, SPM Li concentrations, $\delta^{7} \mathrm{Li}$ values, and suspended sediment concentrations (SSC) exhibit seasonal and depth variations (see Fig. S-4). In contrast, depth profiles performed along the estuarine transect exhibit negligible or small variations, and a noticeable increase can be observed as one moves offshore (Fig. S-5). Generally, depending on the grain size, density, and shape of detrital minerals, hydrodynamic sorting in riverbeds and floodplains may cause mineralogical and geochemical fractionation during SPM transport (Guo et al., 2018). The sediment $\mathrm{Al} / \mathrm{Si}$ ratio allows us to constrain the effects of hydrological sorting on isotope proxies (Dellinger et al., 2014). As shown in Figure 2a, Li/Si ratios positively correlate with $\mathrm{Al} / \mathrm{Si}$ ratios for both riverine SPM (orange symbols) and estuarine SPM (blue symbols), suggesting a dominant control on Li concentrations by Al-rich materials (e.g., clays) present in the SPM (Vigier et al., 2008; Dellinger et al., 2014). Nevertheless, the river and estuary data follow significantly different slopes (Fig. 2a). This cannot be attributed to adsorption in the estuary as exchangeable $\mathrm{Li}$ accounts for less than $1 \%$ of the SPM $\mathrm{Li}$ and thus has a negligible influence on particulate $\mathrm{Li}$ (see Supplementary Information). As indicated by previous studies, this difference in slope can be caused either by ongoing weathering (Lupker et al., 2012) or by a change of sediment source (Yang et al., 2019). In the former case, the steeper slope defined by the estuarine SPM data may indicate clay formation in the estuarine environment. However, the formation of clay minerals along the sampling transect is not supported by XRD results
(Table S-3). On the other hand, $\delta^{7} \mathrm{Li}$ values of SPM samples show no shift toward seawater (Fig. S-3a), in contrast to the altered ${ }^{87} \mathrm{Sr} /{ }^{86} \mathrm{Sr}$ ratios observed in Icelandic estuaries, for instance (Jones et al., 2014). This discrepancy may be explained by the low chemical reactivity of Changjiang-derived SPM, which mainly come from highly weathered and recycled continental sediments and shales. All these observations suggest that SPM Li is not controlled by a chemical process (e.g., watersediment interactions) in the Changjiang Estuary, and a physical process could be the dominant factor, as discussed below.

More information can be inferred from the $\delta^{7} \mathrm{Li} v s$. Li/Al diagram (Dellinger et al., 2017). As shown in Figure 2b, all the river SPM samples are isotopically fractionated compared to their likely parent lithologies because they contain weathering products formed within the basin (Yang et al., 2021). SPM collected in the lower reaches logically represents an average composition of fine particulates from the whole basin. Accordingly, $\delta^{7} \mathrm{Li}$ and $\mathrm{Li} / \mathrm{Al}$ variations of SPM collected at the XLJ station are best explained by a simple binary mixing between sediments collected in the upper Changjiang basin and those from the middle basin (Fig. 2b). In contrast, $\delta^{7} \mathrm{Li}$ and $\mathrm{Li} / \mathrm{Al}$ ratios of SPM collected along the estuarine transect show a distinct trend. From the $\mathrm{C} 1$ site to offshore sites, these values progressively increase towards the binary mixing trend defined between un-weathered shale and igneous rocks (Dellinger et al., 2014). Quartz, feldspar, illite, and kaolinite are four major minerals (i.e. each accounting for $>10 \%$ ) of terrigenous sediments from the Changjiang River (Yang et al., 2002). According to the XRD results, quartz contents in the estuarine SPM increase from $\sim 26 \%$ to $~ 41 \%$ in the offshore direction, while illite and kaolinite contents both decrease by $\sim 10 \%$ (Table S-3). Thus, the trend observed for estuarine $\mathrm{SPM}$ in Figure $2 \mathrm{~b}$ can be explained by a physical loss of clay minerals and/or a gain of Si-rich primary minerals.

Flocculation and resuspension of fine sediments are two fundamental processes occurring in river estuaries. When encountering alkaline seawater, river-borne clay minerals, especially kaolinite, can be easily aggregated and deposited rapidly
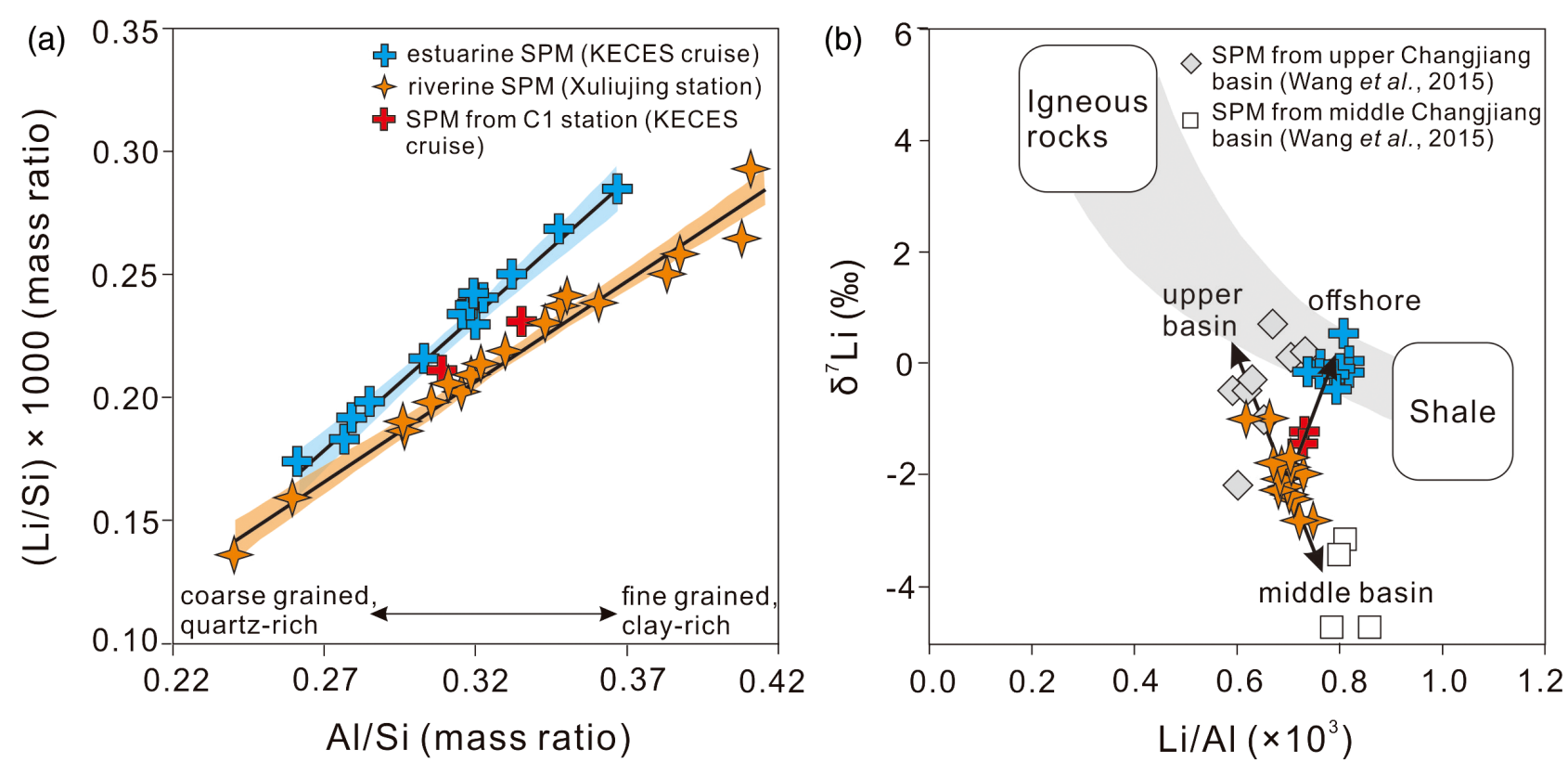

Figure 2 (a) Variations of Li/Si ratios as a function of $\mathrm{Al} / \mathrm{Si}$ ratios for riverine (orange, including the most inland site $\mathrm{C} 1$ in red) and estuarine SPM (blue), and (b) $\delta^{7} \mathrm{Li}$ versus Li/Al ratios for the same samples. The linear correlations between Li/Si and Al/Si are displayed with $95 \%$ confidence intervals (shaded areas). The igneous rocks and shale endmembers in (b) are modified after Dellinger et al. (2014), and the shaded area reflects their mixing. Changjiang River SPM data are from Wang et al. (2015). 
onto the seafloor. Milliman et al. (1985) once estimated that nearly $40 \%$ of the sediment load can be trapped in the Changjiang Estuary during flood season. Seafloor sediments can be resuspended by strong tidal and wind-driven currents, as supported by the several orders of magnitude higher SPM concentration observed at sites $\mathrm{C} 6-\mathrm{C} 8$ than at landward or seaward sites (see Fig. S-5c). Therefore, the offshore transport of SPM in the Changjiang Estuary may result in the preferential flocculation and deposition of clay minerals during the flooding season, while primary minerals or other fine-grained particles tend to be resuspended and carried seaward by currents. Consequently, these physical processes result in a visible increase of SPM $\delta^{7} \mathrm{Li}$ values (by $\sim 1.2 \%$ o) from the most inland site (C1) to the most offshore sites.

\section{Implications for Li Isotopes as Tracers of Continental Weathering}

Previous studies suggest that both the dissolved and particulate $\delta^{7} \mathrm{Li}$ values related to clay formation are powerful tracers of weathering processes. Our results demonstrate that their behaviours are visibly decoupled in the estuary. During estuarine flocculation and resuspension of river-borne fine particles, the SPM $\delta^{7} \mathrm{Li}$ values progressively approach the upper continental crust value. This process is distinct from the general control of hydrodynamic sorting on elemental geochemical compositions during source-to-sink river sediment transport (Lupker et al., 2012; Dellinger et al., 2014). Although the effects of ongoing weathering are negligible in Changjiang-like estuaries, an increase of particulate $\delta^{7} \mathrm{Li}$ values would be expected in rivers draining basaltic terrains (Pogge von Strandmann et al., 2008). Consequently, the utility of detrital $\delta^{7} \mathrm{Li}$ values for tracing past continental weathering in coastal and marginal seas seems to be more complicated than for the isotopic values of the dissolved phase (Yang et al., 2021). Caution should therefore be exercised when using $\delta^{7} \mathrm{Li}$ values, and other similar sediment geochemical proxies, measured in bulk sediments from marginal seas to reconstruct past continental weathering.

Our data along a salinity transect provide the first and clear evidence of the conservative behaviour of dissolved $\mathrm{Li}$ and $\mathrm{Li}$ isotopes during estuarine mixing in a large, particle-rich river. Differing from the case study on Li isotopes in a small Icelandic estuary (Borgarfjörður) draining dominantly basaltic terrains (Pogge von Strandmann et al., 2008), the large Changjiang basin contains various rock types, including intensely weathered shales and $\mathrm{Ca}-\mathrm{Mg}$-depleted sediments. This strongly supports the notion that information on continental weathering carried by the dissolved loads (i.e. $\delta^{7} \mathrm{Li}$ ) of large rivers can be propagated to the ocean without significant modification. Scavenging processes thus have negligible influence on aqueous $\mathrm{Li}$ behaviour, at least in Changiiang-like basins and estuaries, which verifies the assumption of conservative behaviour when using $\mathrm{Li}$ isotopes in marine authigenic archives to reconstruct past continental weathering variations and related carbon cycles (Misra and Froelich, 2012). Additionally, it is noteworthy that $\delta^{7} \mathrm{Li}$ values of estuarine waters significantly increase with seawater addition at low salinities. This highlights the need for precise salinity assessments when sampling estuarine waters for quantifying global $\mathrm{Li}$ and $\delta^{7} \mathrm{Li}$ budgets and continental fluxes to the ocean.

\section{Acknowledgements}

This work was funded by the National Natural Science Foundation of China (Grant No. 41991324, 41730531), the
ANR INTOCC project (ANR-15-CE31-0013), and the China Postdoctoral Science Foundation (Grant No. 2021M692416). Chengfan Yang was supported by the China Scholarship Council for two years of PhD study at the Laboratory of Oceanography of Villefranche-sur-Mer (LOV, France). The KECES cruise was supported by the State Key Laboratory of Marine Geology, Tongji University. We thank Editor Eric H. Oelkers, Morgan T. Jones, and an anonymous reviewer for their constructive comments that greatly improved the quality of this paper. We thank the crew of the Zheyuke- 2 for their assistance with field sampling, Jiantao Cao for his assistance with $\mathrm{pH}$ measurements, Hao Wu for his assistance with suspended sediment concentration measurements, Yanli Li for her assistance with XRD analyses, and Juan $\mathrm{Xu}$ for her assistance with elemental concentration measurements. Many thanks to the $\mathrm{CHOC}$ (Chemistry-Ocean-Climate) team at the LOV for their help with sample pre-treatment.

\section{Editor: Eric H. Oelkers}

\section{Additional Information}

Supplementary Information accompanies this letter at https:// www.geochemicalperspectivesletters.org/article2133.

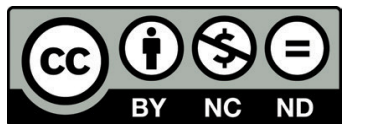

(C) 2021 The Authors. This work is distributed under the Creative Commons Attribution NonCommercial No-Derivatives 4.0 License, which permits unrestricted distribution provided the original author and source are credited. The material may not be adapted (remixed, transformed or built upon) or used for commercial purposes without written permission from the author. Additional information is available at https://www. geochemicalperspectivesletters.org/copyright-and-permissions.

Cite this letter as: Yang, C., Vigier, N., Lian, E., Lai, Z., Yang, S. (2021) Decoupling of dissolved and particulate Li isotopes during estuarine processes. Geochem. Persp. Let. 19, 40-44.

\section{References}

BAgARd, M.L., WeSt, A.J., NEWMAN, K., BAsu, A.R. (2015) Lithium isotope fractionation in the Ganges-Brahmaputra floodplain and implications for groundwater impact on seawater isotopic composition. Earth and Planetary Science Letters 432, 404-414.

Bastian, L., Revel, M., Bayon, G., Dufour, A., Vigier, N. (2017) Abrupt response of chemical weathering to Late Quaternary hydroclimate changes in northeast Africa. Scientific Reports 7, 44231.

Brunskill, G.J., ZAGorskis, I., PfitZnER, J. (2003) Geochemical mass balance for lithium, boron, and strontium in the Gulf of Papua, Papua New Guinea (Project TROPICS). Geochimica et Cosmochimica Acta 67, 3365-3383.

Dellinger, M., Gaillardet, J., Bouchez, J., Calmels, D., Galy, V., Hilton, R.G., Louvat, P., France-Lanord, C. (2014) Lithium isotopes in large rivers reveal the cannibalistic nature of modern continental weathering and erosion. Earth and Planetary Science Letters 401, 359-372.

Dellinger, M., Bouchez, J., Gaillardet, J., Faure, L., Moureau, J. (2017) Tracing weathering regimes using the lithium isotope composition of detrital sediments. Geology 45, 411-414

Gislason, S.R., Oelkers, E.H., Snorrason, A. (2006) Role of river-suspended material in the global carbon cycle. Geology 34, 49-52.

GU, H.Q., MoOre, W.S., ZHANG, L., Du, J.Z., ZHANG, J. (2012) Using radium isotopes to estimate the residence time and the contribution of submarine groundwater discharge (SGD) in the Changjiang effluent plume, East China Sea. Continental Shelf Research 35, 95-107.

GuO, Y.L., YANG, S.Y., Su, N., LI, C., YIN, P., WANG, Z.B. (2018) Revisiting the effects of hydrodynamic sorting and sedimentary recycling on chemical weathering indices. Geochimica et Cosmochimica Acta 227, 48-63. 
HuH, Y., Chan, L.H., Zhang, L., EdmOND, J.M. (1998) Lithium and its isotopes in major world rivers: Implications for weathering and the oceanic budget. Geochimica et Cosmochimica Acta 62, 2039-2051.

JeAndel, C., OelKers, E.H. (2015) The influence of terrigenous particulate material dissolution on ocean chemistry and global element cycles. Chemical Geology 395, 50-66.

Jones, M.T., Pearce, C.R., Jeandel, C., Gislason, S.R., Eiriksdottir, E.S MaVromatis, V., OelKers, E.H. (2012) Riverine particulate material dissolution as a significant flux of strontium to the oceans. Earth and Planetary Science Letters 355, 51-59.

Jones, M.T., Gislason, S.R., Burton, K.W., Pearce, C.R., Mavromatis, V., Pogge von Strandmann, P.A.E., OelKers, E.H. (2014) Quantifying the impact of riverine particulate dissolution in seawater on ocean chemistry. Earth and Planetary Science Letters 395, 91-100.

LaCAN, F., JeAndeL, C. (2005) Neodymium isotopes as a new tool for quantifying exchange fluxes at the continent-ocean interface. Earth and Planetary Science Letters 232, 245-257.

Lupker, M., France-Lanord, C., Galy, V., Lave, J., Gaillardet, J., Gajurel, A.P Guilmette, C., Rahman, M., Singh, S.K., SinHa, R. (2012) Predominant floodplain over mountain weathering of Himalayan sediments (Ganga basin). Geochimica et Cosmochimica Acta 84, 410-432.

Milliman, J.D., Shen, H.T., Yang, Z.S., Meade, R.H. (1985) Transport and desposition of river sediment in the Changjiang Estuary and adjacent continental shelf. Continental Shelf Research 4, 37-45.

Misra, S., Froelich, P.N. (2012) Lithium isotope history of Cenozoic seawater: changes in silicate weathering and reverse weathering. Science 335, 818823.

Morin, G.P., Vigier, N., Verney-CARRON, A. (2015) Enhanced dissolution of basaltic glass in brackish waters: Impact on biogeochemical cycles. Earth and Planetary Science Letters 417, 1-8.

Murphy, M.J., Pogge von Strandmann, P.A.E., Porcelli, D., Ingri, J. (2014) Li isotope behaviour in the low salinity zone during estuarine mixing. Procedia Earth and Planetary Science 10, 204-207.

Pogge von Strandmann, P.A.E., James, R.H., van Calsteren, P., Gíslason, S.R BuRTON, K.W. (2008) Lithium, magnesium and uranium isotope behaviour in the estuarine environment of basaltic islands. Earth and Planetary Science Letters 274, 462-471.

Pogge von Strandmann, P.A.E., Jenkyns, H.C., Woodfine, R.G. (2013) Lithium isotope evidence for enhanced weathering during Oceanic Anoxic Event 2. Nature Geoscience 6, 668-672.

Stoffyn-Egl, P. (1982) Conservative behaviour of dissolved lithium in estuarine waters. Estuarine, Coastal and Shelf Science 14, 577-587.

Tipper, E.T., Stevenson, E.I., Alcock, V., Knight, A.C.G., Baronas, J.J., Hilton, R.G., Bickle, M.J., Larkin, C.S., Feng, L., RelPh, K.E., Hughes, G. (2021) Global silicate weathering flux overestimated because of sediment-water cation exchange. Proceedings of the National Academy of Sciences 118, e2016430118.

Vigier, N., Decarreau, A., Millot, R., Carignan, J., Petit, S., France-Lanord, C. (2008) Quantifying Li isotope fractionation during smectite formation and implications for the Li cycle. Geochimica et Cosmochimica Acta 72, 780-792.

Wang, Q.L., CheTelat, B., ZhaO, Z.Q., Ding, H., Li, S.L., WANG, B.L., Li, J., LiU, X.L. (2015) Behavior of lithium isotopes in the Changiiang River system: Sources effects and response to weathering and erosion. Geochimica et Cosmochimica Acta 151, 117-132.

YANG, C.F., YANG, S.Y., SonG, J.Z., VIGIER, N. (2019) Progressive Evolution of the Changiiang (Yangtze River) Sediment Weathering Intensity Since the Three Gorges Dam Operation. Journal of Geophysical Research: Earth Surface 124, 2402-2416.

YANG, C.F., VigieR, N., YANG, S.Y., ReVeL, M., BI, L. (2021) Clay Li and Nd isotopes response to hydroclimate changes in the Changjiang (Yangtze) basin ove the past 14,000 years. Earth and Planetary Science Letters 561, 116793.

YANG, S.Y., Jung, H.S., CHOI, M.S., LI, C.X. (2002) The rare earth element compositions of the Changiiang (Yangtze) and Huanghe (Yellow) river sediments. Earth and Planetary Science Letters 201, 407-419.

Zhang, Z.L., CaO, Z.M., Grasse, P., Dai, M.H., GaO, L., Kuhnert, H., Gledhill, M., Chiessi, C.M., Doering, K., Frank, M. (2020) Dissolved silicon isotope dynamics in large river estuaries. Geochimica et Cosmochimica Acta 273, 367-382. 